\title{
Long-term changes in adult asthma prevalence
}

\author{
J. Brogger*, P. Bakke*, G.E. Eide", ${ }^{\#, ~ B . ~ J o h a n s e n ~}{ }^{+}$, A. Andersen , A. Gulsvik*
}

Long-term changes in adult asthma prevalence. J. Brogger, P. Bakke, G.E. Eide, B. Johansen, A. Andersen, A. Gulsvik. (C) ERS Journals Ltd 2003.

ABSTRACT: There has been an increase in asthma prevalence among children. Little evidence is available regarding long-term changes in asthma prevalence in adults.

Two cross-sectional studies were performed among adults aged 15-70 yrs in Oslo, Norway, in 1972 and again in 1998-1999 $(\mathrm{n}=39,998)$. A postal self-completed questionnaire was used. Exactly the same questions and survey methods were used in both studies. In 1998-1999, additional telephone follow-up was included for postal nonresponders.

The crude prevalence of ever having had a doctor's diagnosis of asthma increased from 3.4 to $9.3 \%$. The prevalence of wheezing increased from 17.8 to $25.8 \%$ and attacks of breathlessness from 12.6 to $16.7 \%$. After controlling for smoking, the risk of asthma among those aged $<\mathbf{4 0}$ yrs had tripled. The increase in asthma was $\mathbf{5 0} \%$ greater in females than males. The prevalence of symptoms increased less than asthma diagnosis. Wheezing increased by $\mathbf{5 0} \%$ in those aged $<\mathbf{4 0} \mathrm{yrs}$, with smaller increases at greater ages. The increase in symptoms was seen among both asthmatics and nonasthmatics.

There has been a large increase in the prevalence of asthma diagnosis and asthmalike symptoms in adults. The increase is less pronounced among those aged $>\mathbf{4 0}$ yrs. Eur Respir J 2003; 21: 468-472.

\begin{abstract}
* Dept of Thoracic Medicine, Institute of Medicine, University of Bergen, ${ }^{\#}$ Centre for Clinical Research, Haukeland University Hospital, 'Section for Medical Statistics, University of Bergen, Bergen, ${ }^{+}$Dept of Thoracic Medicine, National Hospital, University of Oslo, and Institute of Population-based Cancer Research, Cancer Registry of Norway, Oslo, Norway.
\end{abstract}

Correspondence: J. Brogger, Dept of Thoracic Medicine, Haukeland University Hospital, N-5021 Bergen, Norway. Fax: 4755975149

E-mail: jan.brogger@med.uib.no

Keywords: Asthma epidemiology, epidemiological trends, respiratory signs and symptoms

Received: June 282002

Accepted after revision: October 17 2002

This study was supported by the Norwegian Asthma and Allergy Association and the University of Oslo (both Oslo, Norway) in 1972, and the Norwegian Research Council (Oslo, Norway) and the University of Bergen (Bergen, Norway) in 1998-1999.
Asthma has become a public health issue since the 1960s. The increase in asthma among children is well documented [1-3]. Is this increase mirrored in the adult population? Healthcare utilisation for asthma has increased [4, 5], but this may well equally reflect increasing prosperity, increased focus on asthma or easier access to doctors [6]. There was an increase in mortality during the 1980s [7]. However, death due to asthma is rare and may not reflect the burden of asthma accurately. Prevalence estimates from selected populations have suggested an increase $[8,9]$. Three small short-term studies, two Nordic and one Australian, in adults aged up to 35, 41 and $55 \mathrm{yrs}$, respectively, have shown an increase in the prevalence of asthma [10, 11].

In order to investigate the possible increase in adult asthma for the age group 15-70 yrs over an extended time period, a large-scale cross-sectional general population asthma survey was performed in the city of Oslo, Norway, using the same methods as employed in a previous study in 1972 .

\section{Methods}

\section{Population}

Two serial cross-sectional studies were performed in Oslo in 1972 [12] and 1998-1999. The sampling frame was of individuals aged 15-70 yrs listed in the Central Population Register on December 31, 1971 or 1997 . Registration is mandated by law for all permanent residents of Norway. The sampling was carried out on June 1, 1972 and July 31, 1998. Random samples of the population ( $\mathrm{n}=19,998$ and 20,000, respectively) were selected. The study was approved by the Norwegian Data Inspectorate, Oslo, Norway.

\section{Questionnaire}

A one-page questionnaire designed for self-completion, containing 39 (1972) and 73 (1998-1999) questions on respiratory symptoms and self-reported physician-diagnosed pulmonary and cardiac disorders, was used.

The order and wording of the symptoms and diagnoses examined in the present article were exactly the same in both surveys. Symptom questions were adapted from the Medical Research Council questionnaire [13]. Asthma diagnosis was defined as a positive response to the question "Have you ever been treated by a doctor or been admitted to hospital for one of the diseases mentioned below?", "Asthma". The question on wheezing was "Do you ever have wheezing (whistling sound) in your chest?" The question on attacks of breathlessness was "Do you have attacks of shortness of breath?" 
Table 1.-Age and smoking habit by sex among responders to the Oslo asthma surveys in 1972 and 1998-1999

\begin{tabular}{|c|c|c|c|c|}
\hline & \multicolumn{2}{|c|}{ Males } & \multicolumn{2}{|c|}{ Females } \\
\hline & 1972 & 1998-1999 & 1972 & 1998-1999 \\
\hline Subjects $n$ & 8155 & $7403^{\#}$ & 9539 & $8261^{\#}$ \\
\hline Age yrs & $40.8(40.4-41.1)$ & $40.7(40.3-41.1)$ & $42.0(41.7-42.3)$ & $40.4(40.0-40.8)$ \\
\hline \multicolumn{5}{|l|}{ Smokers } \\
\hline Subjects $\%$ & $57.3(56.2-58.4)$ & $35.2(33.9-36.5)$ & $45.4(44.4-46.4)$ & $33.7(32.4-34.9)$ \\
\hline Cumulative cigarette consumption pack-yrs & $16.0(15.6-16.5)$ & $17.3(16.4-18.1)$ & $9.4(9.1-9.7)$ & $14.0(13.4-14.6)$ \\
\hline \multicolumn{5}{|l|}{ Exsmokers } \\
\hline Subjects $\%$ & $15.7(15.0-16.5)$ & $21.3(20.3-22.5)$ & $8.3(7.8-8.9)$ & $21.8(20.8-22.9)$ \\
\hline Cumulative cigarette consumption pack-yrs & $15.1(14.2-15.9)$ & $13.9(12.9-14.9)$ & $7.1(6.5-7.7)$ & $9.5(8.9-10.0)$ \\
\hline
\end{tabular}

Data are presented as mean or percentage (95\% confidence interval). There were 13371 postal responders and 572 telephone responders to the follow-up in 1998-1999. " : responders in follow-up weighted to account for sampling of postal nonresponders (283 males represent 1134 subjects and 289 females represent 1159 subjects).

Age and smoking habit data are presented in table 1. "Smokers" were daily smokers at the time of the study. "Exsmokers" were persons who had previously smoked daily but had given it up. Cumulative cigarette consumption (in pack-yrs) was computed by dividing the number of cigarettes smoked daily by 20 and multiplying the resultant figure by the duration of smoking (in years). Smoking habits were defined slightly differently in 1972. This has been found to change estimates by $<1 \%[14]$.

\section{Fieldwork}

The questionnaire was posted in November 1972 and in October 1998. Nonresponders were sent a reminder letter with a new questionnaire after 3 and 8 weeks. All mailings included an addressed envelope and return postage.

Due to the lower postal response rate in 1998, follow-up was initiated for nonresponders after 15 weeks. Of the 6,629 postal nonresponders, 222 had actively indicated that they refused to participate, 817 had moved abroad or had no forwarding address, and 68 had other reasons for nonresponse. A $25 \%(1,378$ of 5,522$)$ random sample was drawn from the remaining postal nonresponders. Telephone numbers for the follow-up sample were located using a direct mail firm. Six months after the first mailing, telephone interviews were performed by trained interviewers. At least three contact

Table 2.-Crude prevalence in 1972 and 1998-1999, and adjusted odds ratios (AORs) comparing 1998-1999 with 1972, of asthma diagnosis, wheezing and attacks of breathlessness by sex among responders to the Oslo asthma surveys in 1972 and 1998-1999

\begin{tabular}{lccc}
\hline & 1972 & $1998-1999$ & $\mathrm{AOR}^{\#}$ \\
\hline $\begin{array}{l}\text { Asthma } \\
\text { diagnosis \% }\end{array}$ & & & \\
$\quad$ Males & $3.6(3.2-4.0)$ & $7.6(6.9-8.3)$ & $2.3(1.9-2.7)$ \\
$\quad \begin{array}{l}\text { Females } \\
\text { Wheezing \% }\end{array}$ & $3.2(2.8-3.6)$ & $10.7(9.9-11.5)$ & $3.6(3.1-4.2)$ \\
$\quad$ Males & $20.3(19.4-21.2)$ & $26.3(25.1-27.6)$ & $1.6(1.5-1.8)$ \\
$\quad \begin{array}{l}\text { Females } \\
\text { Attacks of } \\
\text { breathlessness \% } \\
\quad \text { Males }\end{array}$ & $15.6(14.8-16.3)$ & $25.3(24.1-26.4)$ & $1.8(1.6-1.9)$ \\
$\quad$ Females & $11.6(10.9-12.3)$ & $14.0(13.0-14.9)$ & $1.4(1.2-1.5)$ \\
\hline
\end{tabular}

Data are presented as prevalence ( $95 \%$ confidence interval). ${ }^{\#}$ : 1972 is reference (adjusted for age and smoking habit, and separate models for males and females). attempts were made for each subject. Nine months after the start of the study, nonresponders without a regular telephone but with a mobile telephone were located from the two main cellular network providers' databases. A similar mobile telephone interview was performed, using the same wording of questions as in the postal survey.

The mailing of the questionnaires, as well as the telephone interviews, was performed by Statistics Norway, Oslo, Norway. In 1972, questionnaires were reviewed for uncertainties and inconsistencies and interpreted by the investigators [12]. Responses that had been changed during this process were disregarded in the present analyses.

\section{Statistical analysis}

A 95\% confidence interval was computed for all estimates. First, simple multiple logistic regression was performed for each symptom or diagnosis, and the adjusted odds ratio for 1998-1999 versus 1972 estimated while controlling for age and smoking (table 2). This was performed separately for males and females. Then, the crude prevalence of symptoms or diagnosis by age and sex was estimated (fig. 1). Subsequently, a more complex model was used to investigate age, sex and smoking effects in 1972 and 1998-1999. Models were fitted with interactions between study year and each of sex, age and smoking habit. Since changes in the effect of smoking habit

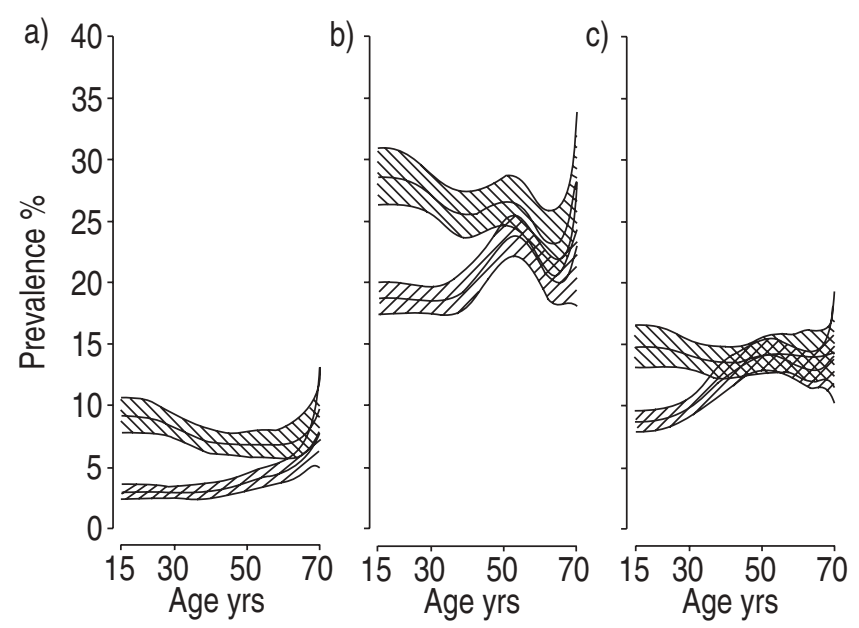

Fig. 1.-Crude prevalence of: a) asthma diagnosis; b) wheezing; and c) attacks of breathlessness by age and study year for males in the

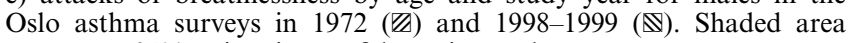
represents $95 \%$ pointwise confidence interval. 


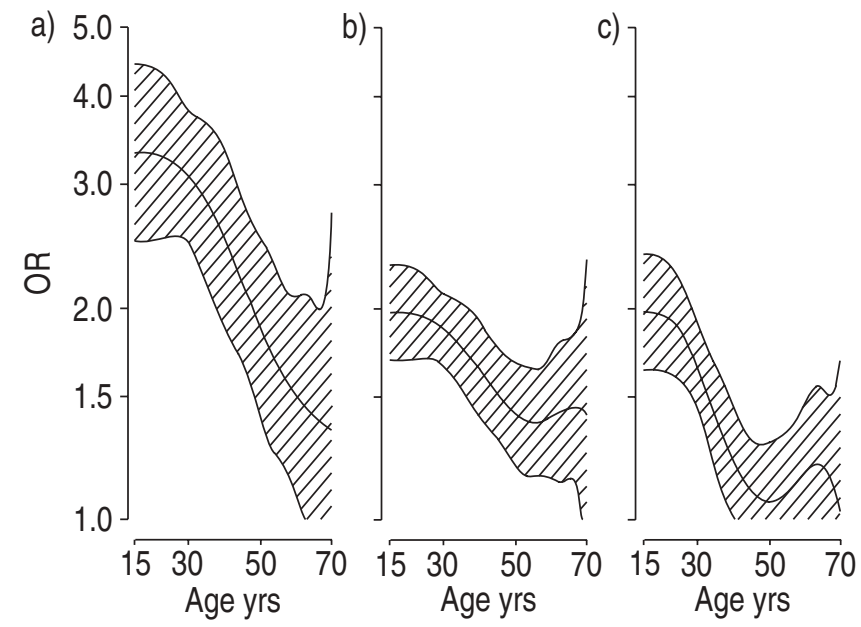

Fig. 2.-Odds ratio (OR) of a change from 1972 to 1998-1999 in: a) asthma diagnosis; b) wheezing; and c) attacks of breathlessness by age for males in the Oslo asthma surveys (adjusted for cumulative cigarette consumption, with interactions as described in text). Log scale on vertical axis. Shaded area represents $95 \%$ pointwise confidence interval.

with study year were not significant for any outcomes, these interactions were subsequently removed. This simpler model is presented in figure 2 and tables 3 and 4 . In order to investigate possible changes in the relationship between symptoms and diagnosis, the prevalence of symptoms in asthmatics and nonasthmatics was then estimated (table 5). The prevalence of

Table 3. - Sex effects for asthma diagnosis, wheezing and attacks of breathlessness by study year among responders to the Oslo asthma surveys in 1972 and 1998-1999

\begin{tabular}{lcc}
\hline & 1972 & $1998-1999$ \\
\hline Asthma diagnosis & $0.92(0.76-1.11)$ & $1.47(1.27-1.70)$ \\
Wheezing & $0.97(0.89-1.06)$ & $1.00(0.90-1.10)$ \\
Attacks of breathlessness & $1.49(1.35-1.65)$ & $1.54(1.38-1.72)$ \\
\hline
\end{tabular}

Data are presented as odds ratio $(95 \%$ confidence interval) (females versus males). Adjusted for cumulative cigarette consumption, with interactions as described in text.

Table 4.-Asthma diagnosis, wheezing and attacks of breathlessness by cumulative cigarette consumption and smoking habit among responders to the Oslo asthma surveys in 1972 and 1998-1999

\begin{tabular}{lcc}
$\begin{array}{l}\text { Cumulative cigarette } \\
\text { consumption pack-yrs }\end{array}$ & Exsmokers & Current smokers \\
\hline Asthma & & \\
5 & $1.01(0.82-1.25)$ & $1.01(0.82-1.24)$ \\
10 & $1.10(0.89-1.35)$ & $1.04(0.85-1.28)$ \\
20 & $1.67(1.25-2.23)$ & $1.27(1.03-1.56)$ \\
Wheezing & & \\
5 & $1.01(0.91-1.12)$ & $1.03(0.93-1.14)$ \\
10 & $1.07(0.97-1.19)$ & $1.23(1.12-1.36)$ \\
20 & $1.47(1.25-1.73)$ & $3.08(2.75-3.44)$ \\
Attacks of breathlessness & & \\
5 & $1.01(0.90-1.14)$ & $1.01(0.90-1.14)$ \\
10 & $1.11(1.00-1.25)$ & $1.11(0.99-1.24)$ \\
20 & $1.82(1.54-2.16)$ & $1.78(1.58-2.00)$ \\
\hline
\end{tabular}

Data are presented as odds ratio ( $95 \%$ confidence interval). Never-smokers in each study year are the reference. Only selected points from smooth curves are shown. Adjusted for cumulative cigarette consumption, with interactions as described in text.
Table 5.-Crude prevalence of symptoms by asthma diagnosis among responders to the Oslo asthma surveys in 1972 and 1998-1999

\begin{tabular}{lccc}
\hline $\begin{array}{l}\text { Self-reported } \\
\text { asthma diagnosis }\end{array}$ & 1972 & $1998 / 1999$ & p-value \\
\hline $\begin{array}{l}\text { Yes } \\
\text { Wheezing }\end{array}$ & $71.7(67.9-75.5)$ & $74.8(72.3-77.2)$ & 0.27 \\
$\quad \begin{array}{l}\text { Attacks of } \\
\text { breathlessness }\end{array}$ & $57.6(53.4-61.9)$ & $61.9(59.2-64.7)$ & 0.34 \\
No & & & \\
$\quad$ Wheezing & $14.3(13.7-14.8)$ & $20.0(19.2-20.7)$ & $<0.0001$ \\
$\quad \begin{array}{c}\text { Attacks of } \\
\text { breathlessness }\end{array}$ & $10.0(9.5-10.5)$ & $12.0(11.4-12.5)$ & $<0.0001$ \\
\hline
\end{tabular}

Data are presented as prevalence ( $95 \%$ confidence interval).

symptoms among asthmatics and nonasthmatics in 1972 and 1998-1999 was also analysed by age, while controlling for smoking.

The generalised linear model was used to fit the logistic regression. Age was modelled as a natural cubic spline (piecewise cubic polynomial) with regression splines (not smoothing splines) [15]. Knots were placed at 15, 25, 40, 55 and 70 yrs. Cumulative cigarette consumption was measured in pack-yrs. This was modelled as two natural cubic spline variables, one for exsmokers and one for current smokers, retaining never-smokers as the reference group. Knots were placed at 0, 10 and 20 pack-yrs.

Subjects with missing answers for an analysis were excluded from that analysis. All calculations accounted for the sampling in the follow-up in 1998-1999 using weighting and robust standard errors. Adjusted Wald tests were used to test the significance of terms.

\section{Results}

The response rate to the postal survey was $88.5 \%(n=17,694)$ in 1972 and $66.8 \%(n=13,371)$ in $1998-1999$. In the telephone follow-up in 1998-1999, 79.7\% of eligible subjects were traceable, of whom $52.1 \%(\mathrm{n}=572)$ responded. This brought the total response rate to $78.3 \%$ in $1998-1999$. Responders to reminder letters and telephone interviews were younger than initial responders, and a greater proportion were smokers (data not shown). The overall response rates were 86.9 and $89.9 \%$ in males and females in 1972 , and 74.7 and $81.9 \%$ in males and females in 1998-1999. There were only weak age trends in the response rates in 1972. In 1998-1999, the response rate was $74 \%$ in subjects aged $<30 \mathrm{yrs}$, increasing to $85 \%$ in those aged $>60$ yrs.

The percentage of smokers decreased and exsmokers increased between the two surveys (table 1). In 1972, there were few female exsmokers. Females had a lower cumulative cigarette consumption than males in both surveys, but a higher cumulative cigarette consumption in 1998-1999 than in 1972.

\section{Prevalence}

The crude prevalence of asthma more than tripled for females and more than doubled for males during the 26-yr study period (table 2). The prevalence of wheezing increased by $62 \%$ for females and $30 \%$ for males and the prevalence of attacks of breathlessness increased by $42 \%$ for females and $21 \%$ for males. Adjustment for smoking made little difference $(<20 \%$ change difference in odds ratio).

The prevalence of outcomes by study year and age for 
males is shown in figure 1. There was an increase in asthma diagnosis and symptoms across the age range; this was more pronounced in those aged $<40$ yrs. The prevalence of asthma increased with age in 1972, whereas the opposite was evident in 1998-1999. Symptoms increased less than asthma diagnosis.

The adjusted odds ratio for a change in symptoms or diagnosis for males is shown in figure 2. The odds ratio for an increase in those aged $<40$ yrs was $>2.5$, and $>2$ up to $50 \mathrm{yrs}$ of age. Wheezing increased by $>50 \%$ in those aged $<40 \mathrm{yrs}$, with the increase levelling off at an odds ratio of 1.5 at $>40$ yrs. Likewise, the increase in attacks of breathlessness was more pronounced in those aged $<40$ yrs.

There was no sex difference for asthma in 1972, but, in 1998-1999, asthma was more common among females than among males (table 3). This means that the increase in asthma among females was $\sim 50 \%$ greater than the corresponding increase among males from 1972 to 1998-1999 at any age $(\mathrm{p}=0.0001)$. There was no sex difference for wheezing in either 1972 or 1998-1999, and no change in the strength of the association $(\mathrm{p}=0.67)$. Attacks of breathlessness were more common among females in both 1972 and 1998-1999, with no change in the strength of the association $(\mathrm{p}=0.68)$.

The association of outcomes with smoking history is shown in table 4. For brevity, the table only shows selected points from a smooth curve. Both asthma diagnosis and symptoms increased with increasing cumulative cigarette consumption. In a separate analysis, whether any change in the effect of cumulative cigarette consumption occurred between study years was tested, and none found (asthma $\mathrm{p}=0.89$; wheezing $\mathrm{p}=0.09$; attacks of breathlessness $\mathrm{p}=0.42$ ).

Adjusting for smoking did not alter the odds ratios comparing 1998-1999 with 1972 by age. For asthma and attacks of breathlessness, the change was $<15 \%$ at all ages. For wheezing, adjustment increased the odds ratio, more among the elderly. For those aged 15-30 yrs, changes were $<15 \%$, whereas changes were $\sim 20 \%$ for those aged $>30$ yrs.

\section{Relationship between asthma diagnosis and symptoms}

Approximately $70 \%$ of self-reported asthmatics reported wheezing and $60 \%$ attacks of breathlessness in both 1972 and 1998-1999 (table 5). The symptoms were analysed by age separately for asthmatics and nonasthmatics, controlling for smoking (data not shown). There was a significant increase in wheezing and attacks of breathlessness among nonasthmatics. For wheezing, the increase was more pronounced in the young $(<40 \mathrm{yrs})$, but the odds ratio was $>1.5$ across the entire age range. For attacks of breathlessness, the increase was confined to those aged $<40$ yrs. For asthmatics, in 1998-1999, there was an increase in symptoms among the young. Since there were fewer subjects with asthma, confidence intervals were wide.

\section{Discussion}

The present study shows that the prevalence of a physician's diagnosis of asthma has increased by a factor of $>3$ in young adults, with increases also occurring in the middle-aged and elderly. The study covers a large time and age span. The sample size is large allowing for precision in estimates, and response rates are high reducing response bias. Exactly the same questions were used in both surveys.

The increase in asthma prevalence may be explained by longer disease duration, higher incidence or both. It is likely that some of the asthmatics in the present study represent part of the increase in childhood asthma during the 1970s and
1980 s, i.e. a cohort phenomenon as the childhood asthma population ages.

There was a marked increase in asthma diagnosis among females, not explained by smoking. This may represent a lower threshold for healthcare utilisation, or increased susceptibility among females to the unknown causal factor or factors behind the asthma increase.

The present findings corroborate those of previous studies in Nordic populations [10,16] and an Australian study [11]. All found increases in asthma prevalence. These studies had small sample sizes and could not provide precise estimates for subgroups. Prevalence estimates were not controlled for smoking. A Norwegian nationwide health survey in 1975 and 1985 found increased prevalence of asthma [17]. It did not ask about asthma but relied on spontaneous reports of asthma as a cause of recent disability or medical attention. Other nonpopulation-based studies have also been published.

One potential weakness of the present study is that a physician's diagnosis of asthma is not validated by objective measures. Although a self-reported physician's diagnosis of asthma is highly specific [18], validation studies were performed at a single point in time. The physician's diagnostic preferences, as well as patients' awareness of and willingness to report asthma, may have changed between 1972 and 19981999. Respiratory symptoms are less subject to these potential biases, and these symptoms have also increased substantially, although to a lesser degree. This implies that the observed increase in asthma prevalence is at least partly genuine.

No large general population studies with biomarkers for asthma (e.g. bronchial hyperresponsiveness to metacholine) were performed in the 1960 s or 1970 s. Consequently, in order to document an increase during this period, studies were restricted to self-reported symptoms and diagnosis, or clinical examination by a physician. Furthermore, there is no objective measure of asthma that can replace the questionnaire diagnosis [6, 19]. A validation study found that the question on "ever asthma" exhibited the greatest validity versus an expert panel of respiratory physicians [20].

Another potential weakness of the present study is the difference in response rate between the two surveys. The response rate was lower in 1998-1999 than in 1972, but still high. The telephone survey in 1998-1999 may have influenced results. In a separate study, good comparability between postal and telephone survey modes was found for the outcomes studied here [21].

The increase in asthma diagnosis is greater than that in symptoms. This may reflect underdiagnosis in 1972. There is some evidence for underdiagnosis in children in the 1970s and 1980s [22, 23]. However, reliable evidence for underdiagnosis in adults over time is scarce, with only recent evidence [24]. This question is unlikely to be resolved. The present authors' clinical impression, however, suggests at least some degree of underdiagnosis in 1972.

The evidence for a genuine increase in respiratory morbidity is strengthened by the fact that the same proportion of asthmatics in both surveys exhibited wheezing and attacks of breathlessness. The increase in symptoms among nonasthmatics may represent undiagnosed asthma, or increased willingness to report symptoms.

Are there confounding variables that explain the observed increase in asthma and asthma-like symptoms? Confounding is not a question of presence or absence but a matter of degree [25]. Adjustment for smoking is often performed in crude categories such as "never-smokers", "former smokers" and "current smokers". It is clear that there can be large differences in cumulative cigarette consumption within each of these categories, resulting in residual confounding [25]. It is desirable to use a more informative measure, such as cumulative cigarette consumption (in pack-yrs). However, there can 
still be significant residual confounding if the cumulative cigarette consumption variable is simply categorised into three or four convenient categories. This type of analysis is also biologically implausible [15]. Within any given interval, for example 10-20 pack-yrs, the effect of smoking is forced to be constant. Then, between $20-21$ pack-yrs, an arbitrary step up is allowed. Regression splines represent a simple means of providing smooth curves, using standard software. In the present analysis, the use of splines also allowed smoother estimation of the effect of age on asthma [26].

Thus, by using cumulative cigarette consumption in packyrs and spline regression, confounding by smoking should be closely controlled for. Patients with chronic obstructive pulmonary disease may misclassify themselves as asthmatics, but this is only likely to be of any significance in those aged $>45 \mathrm{yrs}$, and only if the degree of this misclassification changed between 1972 and 1998-1999. Additionally, and of public health significance, there was no change in the detrimental effect of smoking on asthma and its symptoms.

Adjustment for smoking made little difference to the change in asthma diagnosis between 1972 and 1998-1999. For wheezing, the increase seen without adjustment was even greater among the elderly. This probably reflects an underlying decrease in wheezing due to the decrease in smoking but the increase in asthma kept the prevalence of wheezing higher. Curiously, exsmokers had a greater risk of asthma than current smokers at any given level of cumulative cigarette consumption. This may represent a healthy smoker effect. For symptoms, there was little evidence of any such phenomenon.

There has been a substantial increase in the prevalence of asthma diagnosis in the population, and smaller increases in wheezing and attacks of breathlessness, between 1972 and 1998-1999 in Oslo. It is concluded that the prevalence of asthma in adults has increased in all age groups and that this increase is likely to be genuine.

\section{References}

1. Magnus P, Jaakkola JJ. Secular trend in the occurrence of asthma among children and young adults: critical appraisal of repeated cross sectional surveys. BMJ 1997; 314: 17951799.

2. Nystad W, Magnus P, Gulsvik A. Increasing risk of asthma without other atopic diseases in school children: a repeated cross-sectional study after 13 years. Eur J Epidemiol 1998; 14: 247-252.

3. Downs SH, Marks GB, Sporik R, Belosouva EG, Car NG, Peat JK. Continued increase in the prevalence of asthma and atopy. Arch Dis Child 2001; 84: 20-23.

4. Vollmer WM, Osborne ML, Buist AS. 20-year trends in the prevalence of asthma and chronic airflow obstruction in an HMO. Am J Respir Crit Care Med 1998; 157: 10791084.

5. Senthilselvan A. Prevalence of physician-diagnosed asthma in Saskatchewan, 1981 to 1990. Chest 1998; 114: 388-392.

6. Pearce N. Measuring asthma prevalence. In: Pearce N, ed. Asthma Epidemiology: Principles and Methods. New York, Oxford University Press, 1998; pp. 75-114.

7. Beasley R, Pearce N, Crane J. International trends in asthma mortality. In: Chadwick DJ, Cardew G, eds. The Rising
Trends in Asthma. Ciba Foundation Symposium. Symposium No. 206. Chichester, Wiley; 1997; pp. 140-156.

8. Upton MN, McConnachie A, McSharry C, et al. Intergenerational 20 year trends in the prevalence of asthma and hay fever in adults: the Midspan family study surveys of parents and offspring. BMJ 2000; 321: 88-92.

9. Haahtela $\mathrm{T}$, Lindholm $\mathrm{H}$, Bjorksten $\mathrm{F}$, Koskenvuo $\mathrm{K}$, Laitinen LA. Prevalence of asthma in Finnish young men. BMJ 1990; 301: 266-268.

10. Hansen EF, Rappeport Y, Vestbo J, Lange P. Increase in prevalence and severity of asthma in young adults in Copenhagen. Thorax 2000; 55: 833-836.

11. Peat JK, Haby M, Spijker J, Berry G, Woolcock AJ. Prevalence of asthma in adults in Busselton, Western Australia. BMJ 1992; 305: 1326-1329.

12. Gulsvik A. Prevalence of respiratory symptoms in the city of Oslo. Scand J Respir Dis 1979; 60: 275-285.

13. Brogger J, Bakke P, Gulsvik A. Comparison of two respiratory symptoms questionnaires. Int J Tuberc Lung Dis 2000; 4: 8390.

14. Bakke P, Gulsvik A, Eide G, Hanoa R. Smoking habits and lifetime occupational exposure to gases and dusts, including asbestos and quartz, in a Norwegian community. Scand $J$ Work Environ Health 1990; 16: 195-202.

15. Greenland S. Dose-response and trend analysis in epidemiology: alternatives to categorical analysis. Epidemiology 1995; 6: $356-365$.

16. Linneberg A, Nielsen NH, Madsen F, Frølund L, Dirksen A, Jørgensen T. Secular trends of allergic asthma in Danish adults. The Copenhagen Allergy Study. Respir Med 2001; 95: 258-264.

17. Magnus P, Kongerud J, Bakke JV. Har vi en astmaepidemi? Tidsskr Nor Laegeforen 1991; 111: 972-975.

18. Toren K, Brisman J, Jarvholm B. Asthma and asthma-like symptoms in adults assessed by questionnaires. Chest 1993; 104: 600-608.

19. Pearce N, Beasley R, Pekkanen J. Role of bronchial responsiveness testing in asthma prevalence surveys. Thorax 2000; 55: $352-354$.

20. de Marco R, Cerveri I. An undetected burden of asthma in Italy: the relationship between clinical and epidemiological diagnosis of asthma. Eur Respir J 1998; 11: 599-605.

21. Brogger J, Bakke P, Eide GE, Gulsvik A. Comparison of telephone and postal survey modes on respiratory symptoms and risk factors. Am J Epidemiol 2002; 155: 572-576.

22. Speight AN, Lee DA, Hey EN. Underdiagnosis and undertreatment of asthma in childhood. Br Med J (Clin Res Ed) 1983; 286: 1253-1256.

23. Nystad W, Magnus P, Gulsvik A, Skarpaas IJ, Carlsen KH. Changing prevalence of asthma in school children: evidence for diagnostic changes in asthma in two surveys 13 yrs apart. Eur Respir J 1997; 10: 1046-1051.

24. van Schayck CP, van Der Heijden FM, van Den Boom G, Tirimanna PR, van Herwaarden CL. Underdiagnosis of asthma: is the doctor or the patient to blame? The DIMCA project. Thorax 2000; 55: 562-565.

25. Rothman KJ, Greenland S. Precision and validity in epidemiologic studies. In: Modern Epidemiology. Philadelphia, PA, Lippincott-Raven, 1998; pp. 115-134.

26. Harrell FE Jr. Relaxing linearity assumption for continuous predictors. In: Regression Modeling Strategies: with Applications to Linear Models, Logistic Regression, and Survival Analysis. New York, NY, Springer-Verlag New York, 2001; pp. 16-26. 